\title{
Sociedade da informação: globalização, identidade cultural e conteúdos
}

\author{
Antonio Miranda \\ Coordenador do Grupo de Trabalho sobre Conteúdo e Identidade \\ Cultura, Programa Sociedade da Informação - SocInfo/MCT. \\ cmiranda@unb.br
}

\section{Resumo}

Os conteúdos informacionais nas redes eletrônicas são analisados na perspectiva de seu impacto social e da promoção da identidade cultural. Considera a penetrabilidade e capilaridade das teconologias da informação um dos principais indicadores de desenvolvimento da sociedade da informação e defende a instalação de pontos de acesso à internet em bibliotecas públicas e escolares. Defende também o fomento à produção de conteúdos, seu registro e difusão nos âmbitos de governo, da sociedade pelos indivíduos, de forma a refletir as diversidades culturais e regionais, urbanas, periféricas e rurais, assim como o resgate da memória já registrada em língua portuguesa mas ainda não acessível. O documento foi elaborado com a participação de especialistas de todo o país e serviu de base para a redação do Capítulo 5 do Livro Verde do Programa Sociedade da Informação no Brasil - Socinfo.

\section{Palavras-chave}

Identidade cultural; Conteúdos informacionais; Internet; Sociedade da informação; Socinfo.

\section{Information society: globalization, cultural identity and contents}

\section{Abstract \\ The informational contents in the electronic networks are analyzed from the point of view of its social impact and promotion of cultural identity. Penetration and capilarity of information technologies are considered as the main indicators of development of the information society and it argues on behalf of installing points of access to Internet in public and school libraries. It is also in favor of implementing production of contents, their records and diffusion within the government, of the society by individuals, in order to reflect the cultural and regional, urban, peripherical and rural diversities, as well as the retrieval of the memory already registered in the Portuguese Language, but not yet accessible. The document was written with the participation of experts from all parts of the country and is used as a basis for the elaboration of Chapter 5 of the Green Book of the Program Information Society in Brazil - Soclnfo.}

\section{Keywords}

Cultural identity; Information contents; Internet; Information society; SocInfo.

\section{INTRODUÇÃO}

O Programa Sociedade da Informação, resultante de trabalho iniciado em 1996, pelo Conselho Nacional de Ciência e Tecnologia, tem como finalidade substantiva lançar os alicerces de um projeto estratégico, de amplitude nacional, para integrar e coordenar o desenvolvimento e a utilização de serviços avançados de computação, comunicação e informação, além de suas aplicações na sociedade, de forma a alavancar a pesquisa e a educação, bem como assegurar que a economia brasileira tenha condições de competir no mercado mundial.

Um elemento essencial para a construção da sociedade da informação no Brasil é a implantação de uma sólida plataforma de telecomunicações, na qual possam difundirse e florescer as aplicações em áreas de alto conteúdo e retorno social, como educação, saúde, meio ambiente, agricultura, indústria e comércio. Requer a instalação e o fortalecimento de adequada infra-estrutura de escolas, bibliotecas e laboratórios, a fim de que uma nova geração de brasileiros se prepare para o futuro.

Elementos estruturais - a informática nas suas dimensões de hard e de software; a estrutura de telecomunicações, enquanto rede interligada nacional e internacionalmente; a indústria de equipamentos eletroeletrônicos; os serviços de comunicações e informações, particularmente os informativos e culturais (internet, museus, arquivos, bibliotecas, editoração eletrônica e virtual, publicidade, imprensa, rádio, cinema e TV) - requerem análises em perspectiva. Implica uma reflexão, a um só tempo, sobre a aspiração de modernidade pretendida pelo Programa Sociedade da Informação quanto à realidade objetiva acerca das relações entre os grupos de interesse nacionais e internacionais, governos e pessoas.

O cenário em que estas relações e os elementos estruturais da Sociedade da Informação estão operando comporta três tendências inter-relacionadas:

I. integração vertical, estimulada por desregulação e competição, em um crescente mercado mundial, interligando em um mesmo conglomerado, desde corporações internacionais até empresas locais; 
II. globalização do mercado da produção intelectual, com produtos simbólicos marcados por um caráter crescentemente internacional;

III. privatização, caracterizada pela predominância de interesses privados - em detrimento, muitas vezes, do interesse público -, controlando as empresas e instituições na área das comunicações e da informação.

Quanto à tendência da globalização do mercado da produção intelectual, pode-se argüir que, dentro do quadro de mudanças estruturais por que vem passando o mundo, a disseminação de padrões culturais globalizados vem assumindo proporções sem limite. Tal situação tem se acentuado principalmente porque o modo de produção industrial capitalista tornou-se hegemônico na produção e distribuição de produtos intelectuais e, através de seus mecanismos de distribuição - os mídia em geral-,interfere poderosamente nos processos econômicos, políticos e culturais das sociedades nacionais. Enquanto processo de desenvolvimento de complexas interconexões entre sociedades, culturas, instituições e indivíduos, a globalização estimula e favorece a remoção dos nossos relacionamentos e de nossas referências de vida de contextos locais para contextos transnacionais.

A convergência tecnológica vem eliminando os limites entre os meios, tornando-os solidários em termos operacionais, e erodindo as tradicionais relações que mantinham entre si e com seus usuários. Na verdade, com a tecnologia digital, torna-se possível o uso de uma linguagem comum: um filme, uma chamada telefônica, uma carta, uma artigo de revista, qualquer deles pode ser transformado em dígitos e distribuído por fios telefônicos, microondas, satélites ou ainda por via de um meio físico de gravação, como uma fita magnética ou um disco. Além disso, com a digitalização, o conteúdo torna-se totalmente plástico, isto é, qualquer mensagem, som, ou imagem pode ser editada, mudando de qualquer coisa para qualquer coisa.

A convergência tecnológica parece tender a cancelar a validade de fronteiras entre diferentes tipos de produtos intelectuais e serviços informativo-culturais, bem como a suprimir as linhas divisórias entre comunicação privada e de massa, entre meios baseados em som e em vídeo, entre texto e vídeo, entre as imagens baseadas em emulsão e as eletrônicas e mesmo, a fronteira entre livro e tela. Uma das maiores conseqüências disso é a observável tendência de integração de diversos aspectos das políticas públicas para informática, eletrônica e telecomunicações, com alguns aspectos das políticas relativas aos mídia e à cultura. A Internet, a imprensa, a indústria gráfica, o rádio, a televisão, a biblioteca, o livro e as revistas científicas, as telecomunicações e a informática estão ficando mais interconectadas e interdependentes, de tal forma que uma política de governo para uma delas pode ter significativas implicações para as outras.

Em síntese, os elementos estruturais da sociedade da informação enfrentam hoje, entre outros, dois fortes condicionantes de natureza tanto conceitual quanto contextual: em primeiro lugar, uma retirada progressiva do Estado, em benefício do espaço privado e mercantil, facilitando a acumulação de capital e a mercantilização dos espaços informacionais e culturais.

É importante ressaltar que as formas de atuação do Estado com relação aos elementos estruturais da Sociedade da Informação são cruciais, uma vez que suas políticas podem traçar o horizonte e definir os modos de interação dos indivíduos, grupos, organizações e instituições públicas e privadas, tanto no interior do Estado quanto fora de seus limites institucionais. Foram as políticas seguidas pelos estados-nações do mundo ocidental que levaram, contemporaneamente, o conhecimento e a informação a serem crescentemente apropriados como mercadorias para venda e lucro. É da mesma fonte, portanto, ainda que sustentada por uma sociedade civil, de dimensões nacional e multinacional, que deverão sair as estratégias e caminhos para a democratização da informação.

Independentemente dos caminhos que adotemos na determinação das políticas públicas que nortearão a implantação da sociedade da informação no Brasil, caberia levar em consideração os seguintes conceitos na abordagem do tema:

a) a imprevisibilidade dos caminhos que a inteligência humana fará estes estruturais seguir.

O vertiginoso desenvolvimento das tecnologias de informação e comunicações tem sido um poderoso instrumento para a rotinização, reorganização e automatização do trabalho intelectual. $\mathrm{O}$ fenômeno tecnológico tem operado como liberador de energia cognitiva, que será necessariamente aplicada na área de conhecimento de cada ser humano, não importa seu nível de educação. E dado, que além de liberar energia, o fenômeno tecnológico disponibiliza um fantástico arsenal de ferramentas de concepção e desenvolvimento de produtos e processos, torna-se impossível prever os conteúdos em si mesmos e, mais que isto, as formas que tais conteúdos tomarão, e a maneira como os elementos estruturais se organizarão e se relacionarão entre si e com os consumidores. 
b) A incontrolabilidade dos conteúdos que circulam, sob várias formas, através dos serviços de informações e comunicações.

É da própria natureza dos elementos estruturais da sociedade da informação, sobretudo pelo avanço extraordinário da convergência tecnológica entre informática, comunicações e eletrônica, a incontrolabilidade da produção e circulação de conhecimento. O desenvolvimento tecnológico equilibra a equação social, inventando dispositivos de relativo controle de consumo, pelo menos enquanto se necessita de máquinas lógicas para acessar o conhecimento circulante. Mais importante que isto, contudo, é o fato incontestável de a incontrolabilidade da produção e circulação do conhecimento ser parte constitutiva, estruturante, mesmo, da cultura contemporânea. Ela, por meio das tecnologias de informação e comunicações, realiza e radicaliza o sonho humano libertário.

c) A inevitabilidade de ação pública no setor,

seja regulando - ou desregulando? - ou re-regulando? - a organização, a gestão e a produção, na intenção de garantir o atendimento do interesse público, a ordem democrática, os valores morais e éticos, a livre competição e a busca contínua da universalização do consumo dos serviços de informação e comunicações. Isto leva o Programa Sociedade da Informação, necessariamente, a conceberse como parte, e não todo, no sentido de que somente poderá se realizar, enquanto programa de governo, se estiver afinado com os propósitos, ações e missões das instâncias de governo e agências reguladoras que interferem nos setores de informação e comunicações. As políticas que tenham sido ou forem traçadas para cada um destes setores condicionarão, inevitavelmente, se não todas, parte substancial das diretrizes e ações que se estabeleçam para o Programa.

\section{d) A indutibilidade necessária, por parte do governo,}

de preferência indiretamente, por intermédio de agências específicas, democraticamente instituídas, no sentido de encorajar e fomentar a produção de conteúdos que dinamizem, fortaleçam, preservem e globalizem as identidades e as culturas nacionais. Não se trata, evidentemente, de ação indutora imposta, mas sim resultante de diálogo aberto, pelo qual se possa identificar e priorizar o que e como atender às várias nuances de nacionalidade, inclusive como meio de sedimentação da nacionalidade como um todo. O mercado livre, globalizado, é uma força cujo direcionamento no interior de cada país se faz de acordo com as possibilidades maiores de lucro rápido e vultoso. A uniformidade e a banalização dos valores culturais, sua reinterpretação pela via mercantil e a simplificação de suas complexas, históricas e ricas articulações internas e externas são conseqüências esperadas - e já constatadas - da ação deste mercado falsamente livre, subordinado à economia global. A indução de programas e projetos de ação, e o envolvimento neles dos sistemas formais e não formais de educação, organizações sociais e culturais de atuação local, será fator crucial para tornar a(s) cultura(s) brasileira(s) capaz de dialogar com o global e dele se beneficiar.

\section{OS CONTEÚDOS E A SOCIEDADE DA INFORMAÇÃO NO BRASIL}

Um dos principais indicadores do desenvolvimento da sociedade da informação é a penetrabilidade das tecnologias de informação na vida diária das pessoas e no funcionamento e transformação da sociedade como um todo. Em âmbito geográfico, a penetrabilidade é medida principalmente pelo número de usuários da Internet em uma determinada população. No caso do Brasil, estima-se que, durante o ano 2000, mais de 6 milhões de brasileiros serão usuários da Internet e que, nos próximos cinco anos, poderemos chegar a 30 milhões. Estas cifras, apesar de muito aquém do total da população brasileira ou das porcentagens de usuários relativas ao total das populações nos países desenvolvidos, constituem indicadores significativos do enorme impacto que a Internet está promovendo na sociedade brasileira. Em termos numéricos, estas cifras projetam o Brasil como um dos grandes mercados nacionais da Internet em nível mundial.

Outro indicador fundamental da sociedade da informação, que complementa a penetrabilidade das tecnologias de informação, constitui o nível de operação ubíqua, em um determinado contexto, de recursos, produtos e serviços de informação na Internet por parte dos seus usuários, representando indivíduos, governos e as mais diferentes organizações sociais de caráter público ou privado. Esta operação ubíqua representa a consecução de inovações muitas vezes radicais no funcionamento da sociedade atual, especialmente nas atividades e processos que requerem o acesso à informação.

$\mathrm{Na}$ sociedade da informação, a comunicação e a informação tendem a permear as atividades e os processos de decisão nas diferentes esferas da sociedade, incluindo a superestrutura política, os governos federal, estaduais e municipais, a cultura e as artes, a ciência e a tecnologia, a educação em todas as suas instâncias, a saúde, a indústria, 
as finanças, o comércio e a agricultura, a proteção do meio ambiente, as associações comunitárias, as sociedades profissionais, sindicatos, as manifestações populares, as minorias, as religiões, os esportes, lazer, hobbyes etc. A sociedade passa progressivamente a funcionar em rede. $\mathrm{O}$ fenômeno que melhor caracteriza esse novo funcionamento em rede é a convergência progressiva que ocorre entre produtores, intermediários e usuários em torno a recursos, produtos e serviços de informação afins.

Os recursos, produtos e serviços de informação são identificados na Internet com o nome genérico de conteúdos. Em resumo, conteúdo é tudo o que é operado na Internet. Uma das contribuições mais extraordinárias da Internet é permitir que qualquer usuário, em caráter individual ou institucional, possa vir a ser produtor, intermediário e usuário de conteúdos. E o alcance dos conteúdos é universal, resguardadas as barreias lingüísticas e tecnológicas do processo de difusão. É por meio da operação de redes de conteúdos de forma generalizada que a sociedade atual vai mover-se para a Sociedade da Informação. A força motriz para a formação e disseminação destas redes reside na eficiência das decisões coletivas e individuais. Os conteúdos são, portanto, o meio e o fim da gestão da informação, do conhecimento e do aprendizado na Sociedade da Informação.

Resumindo, a Sociedade da Informação desenvolve-se através da operação de conteúdos sobre a infra-estrutura de conectividade. Portanto, o desenvolvimento da sociedade da informação no Brasil requer, no futuro próximo, um esforço nacional conjugado para aumentar, por um lado, a penetrabilidade da Internet pari passu com o uso adequado de tecnologias da informação (incluindo os softwares potentes e amigáveis, com ergonomicidade) e, por outro lado, o volume de conteúdos brasileiros. Nesse sentido, é de esperar-se que, a partir de um determinado momento do futuro, a interconectividade, expressada pela penetrabilidade das tecnologias de informação convergindo na Internet, será realizada como uma necessidade socioeconômica de operar conteúdos. Em outras palavras, a operação de conteúdos constitui o elemento estratégico nas políticas e programas de promoção da sociedade da informação.

Entretanto, a Internet é dominada pelos conteúdos gerados nos países desenvolvidos. É mesmo aceitável dizer que os indicadores de volume de conteúdos operados por um país na Internet, medidos com relação ao seu Produto Interno Bruto e a sua População, é proporcional ao seu grau de desenvolvimento econômico e social. Mas é justo reconhecer que a questão não é apenas quantitativa, na acepção simplista de que a um maior volume de exposição ou de produção própria de conteúdos necessariamente corresponderiam maiores e mais rápidos índices de desenvolvimento social, porque este requer abordagens mais sofisticadas de interpretação. Incluindo aí as análises relativas à acessibilidade versus uso, custo-benefício e níveis de satisfação de usuários versus disponibilidade.

Pretende-se ressaltar a importância do processo de seleção de conteúdos e dos níveis de qualidade relativa -- no sentido interpessoal - que deverá ser objeto de análise e controle por parte dos sistemas intermediários de informação, mediante instrumentos adequados nas etapas de formação de estoques, processamento técnico e disseminação. Da ação normalizadora e do tratamento parametrizado dos conteúdos, vai depender sua melhor difusão e uso pela sociedade.

Podemos ir mais além e prever que será o volume de conteúdos operados por um país que determinará o seu desenvolvimento econômico e social e a qualidade de vida de seus habitantes. Em um contexto globalizado, o volume de conteúdos operados por um país passa também a medir a sua capacidade de influenciar e de posicionar a sua população no futuro da sociedade humana.

Portanto, aumentar o número e a qualidade de conteúdos nacionais é uma demanda e um desafio enorme que o Brasil está enfrentando hoje, não somente para assegurar a nossa presença futura na rede mundial, mas principalmente para dotar a sociedade brasileira dos recursos, produtos e serviços de informação adequados às nossas necessidades e condições sociais, econômicas e culturais. Nesse sentido, o governo brasileiro, através do Programa Sociedade da Informação, responde a esta demanda com a proposta de promover no futuro imediato um aumento radical na criação e operação de conteúdo nacionais na Internet, em um esforço conjunto das nossas instituições públicas e privadas e, particularmente, de um número crescente de iniciativas individuais.

Devemos reconhecer que a sociedade da informação, em escala planetária, e de forma acelerada, vem desenvolvendo gigantescos estoques informacionais sobre os mais variados temas, em diferentes formatos, para todos os públicos, principalmente nos países mais avançados.

Esse inestimável repertório permite tanto o compartilhamento de conhecimentos, informações e dados, quanto promove o desenvolvimento do capital humano e os princípios da solidariedade entre os povos. 
Mas também pode acarretar alienação dos valores locais, o que vem motivando os governos e as sociedades de quase todos os países à adoção de estratégias para promover a produção e a difusão de estoques de informações nacionais e/ou regionais, como já foi argumentado.

Resumindo, a sociedade se organiza em torno de uma cultura, que é uma maneira de ver o mundo, por meio de um conjunto de idéias implícitas e explícitas, que acabam predominando entre as possíveis.

O conceito de identidade cultural impõe-se nesse contexto, o que implica também noção dos CONTEÚDOS desejáveis e necessários no pretendido processo de informatização/socialização.

\section{CONTEÚDO E IDENTIDADE CULTURAL}

As concepções de identidade cultural vêm transformando-se ao longo do processo civilizatório. Desde aquele sujeito do Iluminismo entendido como totalmente unificado desde seu nascimento, dotado das capacidades de razão, consciência e ação, passando pela idéia mais recente do "sujeito sociológico" que se forma nas relações com outras pessoas que mediam seus valores, sentidos e símbolos expressos em uma cultura. Em tal acepção, projetamos a nós próprios nessas identidades culturais, à medida que internalizamos tais significados e valores, alinhando nossos sentimentos subjetivos com os lugares objetivos que ocupamos no mundo social e cultural em que vivemos. Ou seja, o mundo exterior é que estaria mudando, fragmentando o indivíduo, obrigando-o a assumir várias identidades. Com o agravante de que o ambiente em que vivemos agora é considerado provisório e variável.

O sujeito pós-moderno, conseqüentemente, não tem uma identidade fixa, essencial ou permanente, por estar sujeito a formações e transformações contínuas em relação às formas em que os sistemas culturais o condicionam.

Em outras palavras, o sujeito pós-moderno é definido historicamente, e não mais biologicamente (como preferem os que defendem identidades raciais originais, mas sem bases científicas), porquanto o sujeito assume identidades diferentes em diferentes momentos, afetadas tanto pelos processos de socialização quanto de globalização dos meios de comunicação e informação. A sociedade em que vive o sujeito não é um todo unificado e monolítico, uma totalidade, que flui e evolui a partir de si mesma, pois está também constantemente sendo descentrada e deslocada por forças externas.
Também é válido ressaltar que as identidades são contraditórias e que as pessoas participam de várias simultaneamente, em combinações às vezes conflitantes, tais como ser mulher, pobre, homossexual e negra ao mesmo tempo. Vale também dizer que essa identidade muda com a forma como o sujeito é interpelado ou representado, e que sua identificação nem sempre é automática, que ela precisa ser conquistada e que pode ser alienada politicamente.

Já foi dito com muita propriedade que, em vez de se falar de identidade como uma coisa acabada, deveríamos falar de uma identificação, de um processo, e que essa identidade nunca é plena dentro dos indivíduos, ao contrário, ela precisa ser "preenchida" e desenvolvida.

As identidades nacionais não são nem genéticas nem hereditárias, ao contrário, são formadas e transformadas no interior de uma representação. Uma nação é, nesse processo formador de uma identidade, uma comunidade simbólica em um sistema de representação cultural. E a cultura nacional é um discurso, ou modo de construir sentidos que influenciam e organizam tanto as ações quanto as concepções que temos de nós mesmos.

Não é ocioso lembrar que tais identidades, no caso do Brasil, estão embutidas em nossa língua e em nossos sistemas culturais, mas estão longe de uma homogeneidade - que já não perseguimos -; ao contrário, estão influenciadas (as identidades) pelas nossas diferenças étnicas, pelas desigualdades sociais e regionais, pelos desenvolvimentos históricos diferenciados, naquilo que denominamos "unidade na diversidade". Como todas as nações, mas bem mais do que a maioria delas, somos híbridos culturais e vemos esse processo como um fator de potencialização de nossas faculdades criativas.

A sociedade da informação pretende ser uma dessas forças unificadoras e transformadoras, de cunho globalizante.

A globalização é um processo desigual que, em certa medida, pode ser considerado como a ocidentalização dos valores culturais de nossos tempos. Mas, paradoxalmente, a globalização vem fortalecendo a proliferação de identidades locais e, ainda que pareça utópico, a sociedade da informação que estamos ajudando a construir também pode dar espaço para culturas geograficamente isoladas como é, em parte, o nosso caso. 
Seria justo afirmar que os povos modernos vivem a dialética da tradição e da tradução, que persiste na conservação de suas raízes ao mesmo tempo que busca a transferência de sistemas simbólicos (de umas regiões para outras e também do exterior) que permitam acelerar seu próprio desenvolvimento social e cultural. Ou seja - e este parece ser o caso brasileiro - as culturas híbridas (sincréticas?) constituem um dos diversos tipos de identidade de novo tipo que estão surgindo na pósmodernidade.

O processo de globalização instrumentalizado pela troca acelerada da informação por meio dos novos mídia, que abolem as distâncias e o tempo, não têm provocado a homegeneização completa das culturas e das identidades. Pelo contrário, não apenas antigas querelas identitárias se mantêm vivas, como multiplicam-se diferentes bolsões de identidades locais, de inspiração religiosa, étnica ou comportamental, reanimadas e fomentadas como maneira de resistir à introdução de novos modos identitários uniformizantes. A tendência para a cristalização e difusão de uma ou de algumas poucas linhas de força de alcance global surge como mais nítida no campo da economia do que no campo da cultura.

Esse quadro relativo à identidade cultural não se manifesta apenas no chamado mundo subdesenvolvido ou em desenvolvimento. Países do primeiro mundo vêem na preservação da identidade nacional o instrumento decisivo para autocapacitação não apenas em assuntos culturais como científicos e tecnológicos, com suas claras dimensões econômicas. Medidas de exceção são formuladas para proteger a cultura local em suas mais variadas formas e, mais que isso, é resguardado o próprio idioma nacional, que condensa uma visão de mundo específica - aquela supostamente mais adequada a dar conta de um determinado modo de vida, com seus valores e significados.

Assim, no momento em que o Brasil cuida de criar as condições para sua plena inserção na nova sociedade da informação, é vital que se estabeleça uma política que não se preocupe apenas com a questão econômica e tecnológica dos meios eletrônicos, em particular a Internet, mas que se volte também para os interesses das identidades culturais do país, que constituem seu software mais precioso e livre de direitos autorais.

Levando em consideração, portanto, que será necessário planejar as ações que conduzem à produção e distribuição de conteúdos que sirvam aos interesses da identidades culturais do país, e entendendo por identidade cultural a soma de significados que estruturem a vida de um indivíduo ou de um povo, parte-se do princípio de que será necessário ter em mente, antes de mais nada, que a identidade cultural não é mais uma, porém múltipla.

Há, sem dúvida, uma identidade primária em vigor no país, representada pela língua natural aqui usada e que, no caso do Brasil, é de fato considerada una e unificadora. Os diferentes modos de falar não constituem barreira séria ao entendimento entre a população, e não há, sob esse aspecto, reivindicações identitárias particularizantes. Isso não significa que a fonte de identidade primária do país não deva ser objeto de uma política cultural de apoio pensada para o novo sistema eletrônico de produção da informação. Pelo contrário. Programas específicos devem ser apoiados visando à consolidação do português como idioma privilegiado da Sociedade de Informação Brasileira.

Já quando se trata das identidades secundárias (própria, como exemplo, de regionalismos e grupos de preferências de diversa natureza), o quadro se altera. Será necessário atentar para o fato de que, ao lado da identidade instituída (a identidade "oficial", que vem de cima para baixo e legitima a priori as existências e as propostas, que fornece o padrão ou código geral), manifestam-se diversas identidades instituintes que vêem de baixo para cima e, nesse impulso, conformam o indivíduo, o grupo e a comunidade. Entre essas identidades instituintes, duas chamam a atenção desde logo. De um lado, as de resistência, próprias de minorias étnicas e religiosas e que não raro se alimentam da memória ou do culto das origens. E, de outro, as identidades instituintes de projeto, que podem dizer respeito também a minorias étnicas e religiosas, mas que incluem outros grupos (de defesa da condição feminina ou da ecologia), entre os quais se incluem o dos produtores culturais, que se definem não pelo culto do passado, mas pela idéia de um futuro organizado, e visam não apenas conservar-se em um determinado estado, como também propor novos modos de vida e novas visões de mundo para si e para a comunidade - em uma palavra, que buscam a transformação da estrutura social.

Ao planejar sua entrada na sociedade da informação, o país deverá levar em conta a questão da identidade cultural nessas suas várias manifestações e, de modo especial, não incorrer no equívoco - já observado no passado - de privilegiar apenas as formas identitárias definidas pelo culto da memória ou das origens. Na nova era cultural que se inicia, tão ou mais importante que a identidade vinculada ao passado é a identidade que se projeta para o futuro: é dela que provavelmente virão as respostas aos novos 
desafios e é ela que deve merecer particular atenção. Os efeitos práticos dessa distinção revelam-se desde logo. Quando se pensar, por exemplo, nas maneiras de propiciar a constituição de redes digitais de museus, será preciso levar em conta que os museus são por excelência os depositários da identidade instituída, aquela que já se cristalizou, que goza de um consenso forjado nas instituições culturais do país (escolas, imprensa etc.). Ao lado dos museus existem, porém, alternativas especiais que devem ser contempladas por uma política para a informação de modo a dar espaço a identidades instituintes emergentes.

O adequado equacionamento do jogo identitário no momento em que se intensifica o processo de globalização será vital não apenas para a convivialidade e o florescimento potencial criativo dos indivíduos e grupos, como, de maneira ainda mais acentuada, para acapacidade de governo nacional na sociedade da informação. Sem ela, não haverá condições de participação na conversa cultural, econômica, tecnológica e científica que se esboça na dimensão mundial. Quando falta um interlocutor, o que prevalece é o discurso da imposição. $O$ amparo às identidades culturais nos novos meios eletrônicos terá como resultado benefícios evidentes, já configurados em países que avançaram nesse campo, na forma de incremento da atividade econômica em geral (novos empregos, maior arrecadação de impostos) e desenvolvimento da cidadania (com reflexos diretos sobre o grau de violência urbana). Estes são componentes da capacidade de governo de forma geral, meta por excelência da consciência política de um povo. E, de todo modo, etapa inevitável no processo eventual de integração em blocos - primeiro regionais e, depois, mais largos -, caso se pretenda que essa integração se faça com o respeito às exigências e potencialidades de um povo.

\section{OS PRODUTORES, INTERMEDIÁRIOS E USUÁRIOS DAS REDES DE CONTEÚDOS}

O desenvolvimento de conteúdos na Internet brasileira deverá cobrir, ao longo dos próximos anos, todas as instâncias e atividade sociais, à medida que o governo, as organizações sociais de caráter público e privado, assim como comunidades e indivíduos, passem a operar na Internet suas demandas e ofertas de informação. É através do uso ubíquo dos conteúdos em rede, a sua produção, inovação, veiculação e intermediação no dia-a-dia das instituições e dos indivíduos que a sociedade da informação vai se conformando.
O aumento da importância econômica que a Internet brasileira vem adquirindo sinaliza que a iniciativa privada, com capital nacional e internacional, fará grandes investimentos no futuro próximo para mover a operação dos processos de geração de valor e de comercialização na Internet. Em conseqüência, haverá extraordinário aumento de conteúdos brasileiros relacionados diretamente com as atividades econômicas, comerciais, sociais, culturais e de lazer, comandadas com fins de lucro pela iniciativa privada, incluindo os sítios de comércio eletrônico, investimentos, leilões, sítios institucionais etc. Em particular, velhas e novas empresas ligadas à comunicação e ao lazer investirão em conteúdos de grande popularidade ou orientados a segmentos de públicos específicos em busca da formação de comunidades de usuários que alavanquem retornos econômicos futuros, como são, por exemplo, os portais genéricos e os orientados a públicos específicos, televisões, rádios, jornais, revistas populares etc. A presença ativa das empresas privadas na Internet torna-se progressivamente vital para a sua sustentabilidade e posicionamento no mercado futuro. Este movimento contribuirá para um extraordinário aumento da penetrabilidade da Internet no Brasil, do número de usuários e de conteúdos.

Por outro lado, instituições de caráter público governamentais e não governamentais em todas as áreas são chamadas a operar na Internet conteúdos relacionados direta e indiretamente com o fortalecimento da presença e integração do Brasil no concerto das nações como são a governança, o aperfeiçoamento da democracia e da eqüidade social, a cidadania, a preservação e o desenvolvimento de nossa cultura e história, o fomento ao desenvolvimento econômico, a proteção ao meio ambiente, o fomento à pesquisa científica nacional e a ampla comunicação dos seus resultados, a melhoria da saúde, da educação e, em geral, da qualidade de vida dos brasileiros.

Os conteúdos dos governos federal, estaduais e municipais deverão progressivamente facilitar o exercício dos direitos dos cidadãos, assim como o cumprimento dos deveres públicos das instituições e dos indivíduos com vistas a promover uma transparência progressiva na governança.

As instituições ligadas à pesquisa científica, à tecnologia, à educação e à a saúde deverão operar por meio da Internet, a geração e comunicação de conhecimento, a educação a distância e a promoção da saúde, de modo a contribuir decisivamente para a melhoria da qualidade de vida do brasileiro e ao aumento do chamado capital social do Brasil. 
No que se refere à democratização do acesso à informação e ao conhecimento, os arquivos, as bibliotecas, os museus e os centros de documentação cumprirão um papel estratégico em duas grandes áreas de atuação. Na primeira, como instituições sociais, com a missão e vocação de intermediação que viabilizarão o acesso público, gratuito e assistido aos conteúdos da Internet aos indivíduos e comunidades não conectadas. Este papel será especialmente requisitado nas próximas duas décadas, quando a maioria da população brasileira continuará desconectada. Na segunda área de atuação, estas instituições replicarão na Internet, inovando a partir do conhecimento e experiência acumulada na função de operar coleções de conteúdos organizados segundo metodologias e padrões de seleção e qualidade visando ao seu acesso democrático e à sua preservação para a as gerações futuras. Estas coleções devem incluir, no futuro imediato, o melhor da nossa produção cultural, científica e técnica. Note-se que este caráter de serviço público e de preservação não é objetivo da maioria dos sítios na Internet centrados na veiculação de conteúdos de interesse imediato. Neste sentido, o Brasil deve seguir o exemplo dos Estados Unidos da América e dos países da Comunidade Européia, que estão financiando a operação de conteúdos estratégicos por meio de instituições de caráter público.

Por último, o indivíduo, o cidadão, o usuário, deve ocupar o papel central. É o usuário a razão última da maioria dos conteúdos e processos que se dão na Internet. Mas a Internet coloca o indivíduo no centro não somente como receptor passivo, mas também agente ativo e determinante, livre de escolher o conteúdo, interagir com ele, independentemente do espaço e do tempo em que se localizam o usuário e os conteúdos. Mais que isso, a Internet enriqueceu o papel do usuário, do indivíduo, do cidadão, dotando-o com o potencial e a capacidade de produtor e intermediário de conteúdos. Este fato é notável porque viabiliza a democratização da gestão e do acesso ao conhecimento e permite a realização plena do indivíduo e do cidadão enquanto ser cultural.

\section{DA ORGANIZAÇÃO E DISPONIBILIZAÇÃO DE CONTEÚDOS}

O princípio do "tudo para todos", que anima a concepção da sociedade em rede, levaria a duas orientações aparentemente antagônicas - que, devidamente equacionadas, poderão constituir-se em forças complementares no processo civilizatório, a saber:
- Recursos informacionais externos ao país, possibilitados pela globalização dos meios de comunicação e pela telemática, podem ser utilizados comoinsumos fundamentais para a capacitação, a atualização, a solução de problemas e para a recreação, ou seja, poderão ser transformados em oportunidades e em utilidades para as pessoas, em escala exponencial e inesgotável (porque constantemente atualizável, como um recurso permanente, mas renovável), mesmo considerando-se os riscos de sua exploração e banalização.

O perigo da feudalização dos meios de comunicação e a veiculação de matérias incompatíveis com os princípios da dignidade humana só deverão ser tratados nos marcos dos foros internacionais competentes e no âmbito do estado de direito. Jamais mediante expedientes como a censura, o xenofobismo e outros preconceitos, considerando-se o ideal do livre acesso à informação como um direito humano inalienável.

Deve ser visto como um meio para alargar as fronteiras do conhecimento por parte dos indivíduos e dos grupos humanos, em qualquer lugar e circunstância, ampliando os horizontes da ciência, da cultura e do lazer, promovendo relações mais produtivas e competitivas. Deve-se propiciar a identificação das oportunidades de informação, em escala planetária, que possam apoiar o desenvolvimentos setoriais de atividades de todo tipo, em todo o país, e facilitar sua identificação e uso de forma generalizada. Quando possível, antecipando-se à demanda, criando sistemas de alerta e de disseminação que possam potencializar as oportunidades em benefício do desenvolvimento econômico e social.

Igualmente importante é encontrar formas consorciadas de acesso a produtos e serviços de informação oriundos do exterior, que exijam investimentos de todo tipo, como forma de democratizar o seu acesso e baratear os seus custos, sempre e quando as leis e os compromissos internacionais o permitam.

Em suma, colocar o país nas correntes do saber universal, mediante o compartilhamento do patrimônio cultural da humanidade (apesar das limitações e das barreiras), ampliando a capacidade de tolerância e de respeito entre os povos e as nações.

- Os recursos de informação produzidos no Brasil, pretéritos e contemporâneos, requerem um tratamento técnico privilegiado para garantir sua disponiblidade e acessibilidade a todos os possíveis interessados, pari passu com o incentivo à sua divulgação e uso intensivo em todos os níveis e em todos os lugares. 
É de interesse da sociedade brasileira acelerar o registro, o armazenamento e a promoção de dados, informações e conhecimentos sobre o país, nos níveis de governo, sociedade e indivíduos como geradores e promotores.

A existência de uma extensa e moderna infra-estrutura de acesso à informação, por si só, já desencadeia forças criativas e produtivas em escala considerável, mas também requer estratégias adequadas para fomentar a melhor distribuição das oportunidades e a mais justa representatividade nacional.

Para a conquista desses objetivos sociais, faz-se imprescindível, dentre os muitos pré-requisitos necessários, os seguintes:

·a universalização do ensino formal e da educação continuada como condição de ingresso da população brasileira na era do conhecimento,

-o treinamento massivo no uso das novas tecnologias interativas, de forma generalizada e em todos os níveis, como ferramenta de participação nas redes e sistemas do Programa Sociedade da Informação, como meios de promoção social social, geração de empregos qualificados e melhoria da qualidade de vida.

A Internet está sendo canal para a veiculação de conteúdos tradicionais e também de novos formatos - tais como emails, listas de discussões etc. - que têm peculiaridades e usos específicos, tanto de forma isolada quanto combinada. Será necessário familiarizar-se com cada um desses tipos, conhecer suas potencialidades de utilização para fins determinados e, não menos importante, desenvolver formas adequadas para sua correta identificação e controle do ponto de vista técnico. A descrição correta desses itens informacionais é condição para seu adequado registro e entrada de dados nos sistemas de informação, premissa básica para garantir uma recuperação mais pertinente.

O que é importante ressaltar é que essas fontes de informação compreendem, como já foi mencionado, diferentes formatos - tais como artigos científicos, dados estatísticos, descrições de produtos etc. -, oriundos de diversos e variados suportes (papel, microfilme, vídeo etc) que necessitam de normas próprias para sua devida organização e tratamento nas tarefas de armazenamento e recuperação. A identificação desses tipos e seu equacionamento técnico diferenciado poderá facilitar as tarefas de organização dos estoques e de construção de serviços tais como bibliotecas virtuais, portais e uso em conferências eletrônicas ou provisão de documentos, dentre outros.

\section{PRINCÍPIOS GERAIS PARA UMA POLÍTICA SOBRE CONTEÚDOS E IDENTIDADE CULTURAL}

- Os conteúdos de identidade cultural devem preservar e estimular a diversidade em suas variadas manifestações no espaço (identidades instituídas e instituintes) e no tempo (a memória e o projeto como fontes de formação de identidades culturais).

- As autoridades públicas devem acompanhar o sistema de produção de conteúdos (em suas diferentes fases: a produção propriamente dita, a distribuição, a troca e o uso) sob o ângulo da identidade cultural de modo a assegurar o pleno uso social das possibilidades da sociedade da informação.

Para tanto, será necessário:

a) criar um ambiente legal adequado à nova realidade informacional em relação aos conteúdos com identidade cultural, não só no marco das regulamentações técnicas e de proteção dos direitos autorais, mas também de garantias de acesso e uso nos limites do direito à informação como um direito humano fundamental;

b) apoiar a pesquisa em tecnologia de produção e comunicação de conteúdos com identidade cultural, para facilitar seu estocamento e disseminação em padrões que permitam sua identificação; conversão e compartilhamento da forma mais desimpedida possível, no marco legal adequado e ergonomicamente correto;

c) criar as condições para a capacitação universal dos cidadãos em relação às novas tecnologias, contribuindo para minimizar a exclusão social, de forma a atenuar ou superar as disparidades regionais, ampliando-se as oportunidades de acesso às fontes disponíveis na rede;

d) manter as instituições culturais públicas em condições de pleno uso das potencialidades da nova tecnologia de conteúdos com identidade cultural, por meio de fomento e de incentivos ao seu pleno e permanente desenvolvimento.

Cabe ressaltar, na mesma linha de raciocínio, que a questão dos conteúdos depende da capacidade de organização de nossas instituições no tocante aos seus acervos informacionais. 
Os conteúdos estarão sempre sendo produzidos e armazenados de forma descentralizada e dispersa, exigindo enorme esforço para atraí-los e incorporá-los como serviços e produtos mediados pela rede de acessos propostos pela sociedade da informação.

Tanto a informação já armazenada quanto a que continua sendo produzida requerem um tratamento adequado para sua incorporação à rede, em um esforço de integração de recursos e de promoção de seu compartilhamento responsável. O que implica garantir a disponibilidade dos acervos de instituições (bibliotecas, arquivos, museus, coleções particulares etc.) como de todo e qualquer agente social produtor de informações, mediante seu tratamento técnico requerido pelo sistema. Requer ainda a montagem de um esquema de acessibilidade que, mesmo facilitado pela infra-estrutura da rede, requer a celebração de acordos e normas para sua distribuição e uso.

Dos princípios enunciados, derivam-se as seguintes diretrizes:

- a produção de conteúdos para a Internet considera o acesso universal e eqüitativo à rede;

- a produção de conteúdos produzidos no Brasil ou sobre o país devem ser disponibilizados na Internet;

- reempacotamento ou realinhamento: os conteúdos já produzidos no ou sobre o país deverão ser reempacotados ou realinhados para facilitar sua disponibilização na Internet;

- conteúdos integrados à rede deverão ser também divulgados por outros meios (tais como cds, vídeos etc.) para atender ao público que ainda não tem acesso à rede;

- ação integrada de produção de conteúdos com outros países de língua portuguesa;

- produção e integração de conteúdos à rede deverão ser orientados pelas políticas públicas setoriais;

- criação de mecanismos para divulgação de conteúdos produzidos em outros países de acordo com as estratégias próprias de políticas públicas setoriais;

- criação e disponibilização livre e irrestrita de metodologias e tecnologias que possam promover a construção e acessibilidade de conteúdos por setores menos privilegiados da sociedade.

\section{DIRETRIZES PARA PROMOÇÃO DE REDES DE CONTEÚDOS NACIONAIS}

Considerando os objetivos e pressupostos anteriores, cabem as seguintes orientações:

- viabilizar o acesso às fontes de conhecimentos, informações e dados produzidos/registrados pelo governo, pela sociedade e pelos indivíduos que constituem a nação brasileira;

- valorizar a produção e a difusão de registros informacionais de todo tipo em língua portuguesa, como forma de promover o autoconhecimento e a autoestima do povo brasileiro;

- propiciar o registro das expressões culturais, artísticas, religiosas e científicas, em qualquer mídia, também em línguas indígenas, assim como nas dos povos africanos e de outras nacionalidades que contribuíram para a nossa formação social, visando a preservar e manter vivas as origens da nação brasileira, em seus aspectos multiéticos e multiculturais;

- facultar a produção, armazenamento, difusão e o uso de conteúdos que reflitam os interesses de regiões menos desenvolvidas, de áreas periféricas e rurais, como forma de reduzir as disparidades regionais;

- dar oportunidade às minorias étnicas, sociais e políticas para o registro e difusão de suas manifestações e idéias, como forma de diminuir as desigualdades sociais;

- criar canais próprios para os deficientes físicos, analfabetos e cidadãos de menor poder aquisitivo, para promover a justiça nas oportunidades de acesso à informação;

- promover o acesso à produção artística, cultural e científica gerada por nossas instituições, seja mediante a oferta de metodologias/tecnologias para sua organização, seja mediante o financiamento de projetos prioritários;

- promover o acesso ao acervo internacional disponível em rede para ampliar a nossa capacidade de atualização e de inserção na comunidade global, sobretudo para o uso dos recursos que possam alavancar o nosso próprio desenvolvimento e ampliar a competitividade de nossas indústrias e atividades criativas; 
- ampliar os canais de comunicação com os países do Mercosul, com as nações do continente e das línguas latinas em geral, com as regiões do mundo das quais os brasileiros descendem, assim como uma aproximação com todo e qualquer Estado que se abra a este diálogo para a ampliação dos vínculos culturais, econômicos e sociais indispensáveis para uma convivência pacífica e solidária.

\section{OBSERVAÇÃO FINAL}

Este texto foi elaborado sob a coordenação do professor doutor Antonio Lisboa Carvalho de Miranda (doutor em Ciência da Informação e Chefe do CID/UnB) pelo Grupo de Trabalho sobre Conteúdo e Identidade Cultural da SocInfo. O presente trabalho foi realizado com as contribuições do referido grupo, a saber: Abel Packer
(Bireme), Abigail de Oliveira Carvalho (UFMG), Aldo de Albuquerque Barreto (IBICT/MCT), Fernando Flávio Pacheco (PUC/PR), José Marques de Mello (USP), José Teixeira Coelho Netto (MAC/SP), Nelson de Castro Senra (IBGE), Othon Jambeiro (UFBA) e Yone Sepúlveda Chastinet (CNPq/Prossiga).

O relatório final do GT inclui, além deste texto, todo um conjunto de diretrizes específicas e sugestões programáticas a serem implantadas pelo Programa Sociedade da Informação. O embasamento teórico que sai nesta edição aparece de forma muito resumida no texto do Livro Verde do Programa SocInfo, que estará sendo divulgado em forma impressa e pela Internet, assim como parte das sugestões programáticas e outras linhas de ação propostas pelo GT, que foram totalmente excluídas do presente artigo. 